\title{
Research and Practice of Flip Classroom Based on WeChat Platform Combined with Formative Evaluation in Teaching
}

\author{
Xianjiu Liao, Yan Li, Qichuan Huang, Suoyi Huang, Qianli Tang* \\ Youjiang Medical University for Nationalities, Baise, China \\ Email: ^htmgx919@163.com
}

How to cite this paper: Liao, X. J., Li, Y., Huang, Q. C., Huang, S. Y., \& Tang, Q. L. (2020). Research and Practice of Flip Classroom Based on WeChat Platform Combined with Formative Evaluation in Teaching. Creative Education, 11, 1552-1560.

https://doi.org/10.4236/ce.2020.118113

Received: August 9, 2020

Accepted: August 28, 2020

Published: August 31, 2020

Copyright $\odot 2020$ by author(s) and Scientific Research Publishing Inc. This work is licensed under the Creative Commons Attribution International License (CC BY 4.0).

http://creativecommons.org/licenses/by/4.0/

\begin{abstract}
Objective: This paper constructs a joint teaching mode based on the WeChat flip class and formative evaluation, which is applied in the teaching of Analytical Chemistry, and explores its teaching effect. Methods: We adopted the new teaching mode with the students of Pharmacy in our university as the teaching objects, and then investigated on the learning effect and experience of the teaching objects via questionnaire after the teaching. Results: The research objects were satisfied with the learning effect and experience brought about by the new teaching mode, indicating that the teaching effect was good. Conclusion: The teaching mode based on WeChat flip classroom and formative evaluation can construct a relatively fair evaluation system, trigger students' interest in learning, promote their independent learning, effectively overcome their weariness of analytical chemistry, and effectively improve the teaching effect of analytical chemistry, which is worthy of continuous optimization and promotion in teaching.
\end{abstract}

\section{Keywords}

WeChat, Flip Classroom, Formative Evaluation, Internet Plus, Mobile Learning, Analytical Chemistry, Medical Universities

\section{Introduction}

Analytical chemistry is indispensable for such operations in medicine and health as clinical test and diagnosis, pathological mechanism research and drug quality control. Analytical chemistry, with more knowledge points than most of other disciplines, feels relatively abstract for medical students, especially, the instrumental analysis which introduces lots of abstract contents such as instrument structures and analytical method principles, resulting in great difficulty for stu- 
dents to comprehend them (Wang, Zhang, Shi, Wang, \& Li, 2019). In addition, the short-cycle course students in Youjiang Medical University for Nationalities are mostly from the remote minority areas in West China, whose entrance scores are relatively poorer with a weak knowledge reserve in chemistry. Some of them did not even choose chemistry as a college entrance examination subject; thus their knowledge reserve in chemistry was pretty weak as a whole. The above-mentioned factors led to a fact that the short-cycle course students as the research objects took analytical chemistry as a difficult subject to master. It was common for students to be weary of it before starting to learn. Therefore, creating a pleasant learning atmosphere was thought to be an effective way to eliminate their weariness for the subject.

Flip class was nominated as "a significant technological change affecting classroom teaching" in 2011 by Globe and Mail, Canada. In the teaching mode of flip class, learners are required to find problems by independent learning before lecturing, and such problems will be solved by teacher-student cooperation in classroom (Ma, Cai, Li, Na, Song, \& Xu, 2018). Since the short-cycle course students from remote minority areas are usually weak in self-control, the shortage of teachers' supervision would definitely reduce the effect of independent learning at the stage of assimilation in flip class. When looking for countermeasures, we found that WeChat could assist the communication between teachers and students, which was conductive to the management; the formative evaluation, as the statistics and evaluation at different stages of learning, could also help supervise the students' learning.

The formative evaluation overcomes a defect in summative evaluation, i.e. neglect of students' progress, attitude, effort and strategies while learning, which is aimed to "stimulate students to learn, and help them regulate the learning process effectively, enable them to obtain a sense of achievement, enhance their self-confidence, and cultivate a team spirit" (Weng, 2018). Nevertheless, the lack of real-time data collection methods and technical support restricted the large-scale application of formative evaluation. With the "Internet plus" era mobile era and the popularity of smart phones came an increasing number of active WeChat users; so far, most of the college students have adopted smart phones and WeChat as their basic communication means. In such context, the teaching may introduce WeChat to realize a whole-course formative evaluation system, including classroom sign-in and in-class test.

A kind of consistency exists between flip classroom, WeChat and formative evaluation. The teaching mode of flip classroom, with WeChat as the channel for teacher-student communication and management, requires formative evaluation for instruction, promotion and feedback; the formative evaluation can realize an in-process evaluation by flip class on students' performance in pre-class learning and classroom activities; WeChat is equipped with a powerful statistical analysis, and thus conducive to the implementation of formative evaluation. Therefore, we constructed a teaching mode of WeChat flip class and formative evaluation, to male an in-depth integration between information technology and teaching, 
so that learning could be done "everywhere and anywhen"; the formative evaluation mode based on WeChat can collect evaluation basis easily, which eliminated the lack of evaluation evidence, making the formative evaluation system run through the whole teaching and learning process effectively, and thus conductive to timely feedback at each stage of teaching. The mode makes students more clear of their learning objectives, gets them stimulated and exercised, and strengthens their learning motivation and self-confidence.

\section{Research Objects and Methods}

\subsection{Research Objects}

The 2018 Chinese Medicine Specialty Class of Youjiang Medical University for Nationalities is selected as the experimental subject, with a total of 99 students. The course of analytical chemistry is scheduled in the second semester of the first grade and includes 72 hours, of which 51 hours are theoretical and 21 hours are practical. The 3rd edition Analytical Chemistry textbook edited by Qiu Ximin of China Medical Science and Technology Publishing House is adopted.

\subsection{Research Methods}

WeChat-aided Teaching Platform was employed while teaching, where teachers uploaded such teaching resources as teaching objectives, courseware, assignments and evaluation standards; in the classroom, WeChat was employed to assist such activities as sign-in, quiz and discussion, which made it possible to carry out online and offline teaching activities flexibly and easily; after class, the learning resources were provided via WeChat to help students expand their knowledge and present their achievements. The comprehensive performance of students $=$ formative evaluation scores $(40 \%)+$ final scores $(60 \%)$. We generated and recorded the scoring of such activities as attendance, online assignments, online voting, online exercise and classroom discussion via WeChat, made timely feedback and encouraged students to progress, thereby stimulating students' enthusiasm in learning. The course assessment based on WeChat flip class and formative evaluation involves 1) Pre-class knowledge instruction: 10\% of total scores, including independent learning, online discussion, online test, etc.; 2) Assimilation of knowledge during class: $15 \%$ of total scores, including group discussion, Q\&A, practical operation, online assignments, etc.; 3) After-class consolidation and development: $15 \%$ of total scores, including participation in feedback evaluation, experimental video, completion of expansion tasks, etc. The research introduced WeChat into the formative evaluation of analytical chemistry, and transformed the evaluation into a mode involving attendance, in-class test, classroom questioning, online assignments, classroom discussion, offline assignments, etc. The evaluation system, with its emphasis on both result and process, reflected the students' learning status in a relatively dynamic, objective and comprehensive way, which facilitated the development of students' comprehensive quality and gave full play to students' learning initiatives. 


\subsection{Effectiveness Evaluation}

At the end of the curriculum, 54 students were selected at random for a questionnaire in which the students were required to evaluate the learning effect and experience regarding the joint teaching mode based on WeChat flip class and formative evaluation. All the items in the questionnaire were scored by Likert5, which involved learning experience evaluation (Table 1) on 8 aspects, including pre-class resource transfer, classroom atmosphere and knowledge expansion after class, and the evaluation based on students' satisfaction with the new teaching mode (Table 2).

\subsection{Statistical Results}

SPSS 22.0 software was adopted in the data analysis. The enumeration data was represented in $\mathrm{n}(\%)$, and the measurement data was represented in $(\bar{x} \pm s)$.

Table 1. Evaluation on learning experience (\%).

\begin{tabular}{cccc}
\hline Survey items & Very satisfied & Satisfied & Satisfaction rate \\
\hline Pre-class self-learning instruction & 46.30 & 48.15 & 94.44 \\
Pre-class resource transfer & 48.15 & 46.30 & 94.44 \\
Improvement learning abilities in fragment time & 35.19 & 55.56 & 90.74 \\
Classroom atmosphere & 50.00 & 46.30 & 96.30 \\
Convenient sign-in & 50.00 & 44.44 & 94.44 \\
Knowledge expansion & 53.70 & 40.74 & 94.44 \\
Interaction between teachers and students & 42.59 & 48.15 & 90.74 \\
In-time feedback for the evaluation & 42.59 & 48.15 & 90.74 \\
Fair and credible evaluation & 51.85 & 40.74 & 92.59 \\
Total average score & 46.71 & 46.50 & 93.21 \\
\hline
\end{tabular}

Table 2. Learners' recognition of the new teaching mode (\%).

\begin{tabular}{lccc}
\hline \multicolumn{1}{c}{ Survey items } & Completely agree & Agree Consent rate \\
\hline $\begin{array}{l}\text { Do you think it is necessary to employ a new teaching mode? } \\
\text { Do you look forward to a new teaching mode? }\end{array}$ & 59.26 & 35.19 & 94.44 \\
$\begin{array}{l}\text { Do you think the new learning mode is conducive to } \\
\text { independent learning? }\end{array}$ & 59.26 & 37.04 & 96.30 \\
The new learning mode helps expand the classroom teaching & 57.41 & 40.74 & 98.15 \\
The new learning mode can build a relatively fair evaluation & 59.26 & 33.33 & 92.59 \\
system & & 46.59 \\
The new learning mode can build a harmonious classroom \\
atmosphere
\end{tabular}




\section{Results}

\subsection{Investigation on the Learning Experience}

In the historical context of mobile phones and Internet, there are lots of "phubber" and "phone freak" among the contemporary short-cycle course students in colleges. At present, most of the short-cycle course students in our university are weak in their knowledge reserve of chemistry and learning motivation, who are not interested in analytical chemistry. Nevertheless, they tend to accept new things with their courage to have a try. We can employ online teaching platforms and mobile terminals when providing students with rich resources of independent learning, thereby improving their learning experience. According to the questionnaire on the students' learning experience as shown in Table 1, their average satisfaction rate regarding the teaching mode based on WeChat flip class and formative evaluation is as high as $93.21 \%$, with the most concentrated scoring range at "very satisfied", accounting for $46.71 \%$ on average; following the "very satisfied" is "satisfied", accounting for $46.50 \%$ on average; since there were few students who were "unsatisfied" or "very disappointed" (or the proportion was extremely low), the remaining scoring ranges basically fell into the general ranges. The teaching mode based on WeChat flip class and formative evaluation can effectively promote the interaction between teachers and students. Therefore, previously rigid and boring course of analytical chemistry is greatly improved, and the classroom atmosphere becomes more active.

\subsection{Investigation on the Learners' Recognition of the New Teaching Mode}

Upon the completion of course, a questionnaire was conducted among the students on their recognition of the new teaching mode. According to the result (Table 2), their scoring range of the new teaching mode was concentrated at "completely agree", accounting for $53.94 \%$ on average; following the "completely agree" is "agree", accounting for $41.90 \%$ on average; the total average consent rate is $95.83 \%$. Since there were few students who were "disagree" or "object" (or the proportion was extremely low), the remaining scoring ranges basically fell into the general ranges. In the new teaching mode, teachers and students exchange their roles, with students in the dominant position. According to the investigation result, the new teaching mode was recognized by students.

\subsection{Learners' Final Results}

In addition, the short-cycle course students in the University are mostly from the remote areas in West China, whose entrance scores are relatively poorer with a weak knowledge reserve in chemistry. Some of them did not even choose chemistry as a college entrance examination subject, thus their knowledge reserve in chemistry was pretty weak as a whole. Nevertheless, one semester of hard work improved the final comprehensive performance to $(68.94 \pm 7.91)$, marking a great progress in their examination results. In addition, according to the teach- 
ing evaluation results in the educational administration system, the average scoring by students on their teachers was 94.85 , indicating that students were satisfied with the academic performance and teaching effect.

\section{Discussion}

Information-based education is an inevitable trend in the era of "Internet plus Education". To construct information technology supported and student-centered teaching mode with the focus on students' all-round development is desperately needed in the teaching reform. The traditional evaluation mode, featured with the strong utilitarianism, ignores the affirmation on the progress made by students while learning, thus failing to feedback students' learning status in time. The neglect of evaluation on such non-intellectual factors as emotion and attitude sets the traditional mode in serious limitations, thus restricting students' all-round development (Wang, Gong, Zhu, Yang, Gao, He, Lin, \& Bu, 2020). Since a kind of consistency exists between flip classroom, WeChat and formative evaluation, we can conduct such activities as attendance confirmation, in-class test, classroom questioning and classroom discussion via WeChat to implement the formative evaluation in the whole teaching process, thereby stimulating students' interest in learning and improving their self-learning ability.

1) The weariness of learning decreased significantly, with the students' interest in learning stimulated

In the era of "Internet plus Education", teachers can use the online teaching platform and offline teaching modes to provide students with learning paths and rich resources for independent learning by means of classroom teaching and modern information technology, to present the learning contents in such digital ways as video, to make the course more vivid and expressive, to provide students with more sensory stimuli, and to reduce their weariness of learning while carrying out formative evaluation via WeChat, supervising and instructing on their learning (Chen, 2017). While carrying out the formative evaluation, students were required to participate in such links as classroom questioning and classroom discussion, which transformed the students from "passive learning" to "active learning", stimulated students' interest in learning analytical chemistry and enlivened the classroom atmosphere. The students got timely feedback from the teachers, were encouraged and instructed while enjoying the fun in learning. The active atmosphere while classroom discussion transformed the course of analytical chemistry from "obsolete" to "popular", is closer to students' life, and helps improve their learning enthusiasm. According to the results of the questionnaire, $94.44 \%$ of the students thought that the interaction between teachers and students in the new teaching mode was more effective; $96.30 \%$ thought that the new learning mode and teaching activities were colorful; $96.30 \%$ thought that the new learning mode could construct a harmonious classroom atmosphere.

In addition, the early video shooting and later interaction for the teaching 
mode based on WeChat flip class and formative evaluation requires teachers to spend more time and energy. Moreover, such teaching mode practices the "student-centered" concept, in which teachers must update their teaching concept, redefine their roles, improve their information literacy, enhance their information-based teaching ability, and innovate their teaching modes. The students as experimental subjects in the research gave a highly positive evaluation on their teachers. According to the teaching evaluation results in the educational administration system, the average scoring by students on their teachers is 94.85 (85 students participated in the evaluation, full score: 100), suggesting that the teachers' efforts were recognized by their students. $94.44 \%$ of the students thought it necessary to implement the new teaching mode; $96.30 \%$ desperately expected that the future application of new teaching mode in other courses.

2) Evaluation effect was improved based on the quantitative evaluation of mobile platforms

The most important role of formative evaluation is to find out the problems while teaching by different evaluation means and to make timely adjustments. However, limited by energy and other factors, the traditional formative evaluation tends to lag behind in the evaluation of students, which cannot provide timely feedback; in addition, the formative evaluation has to be based on objective and comprehensive data and materials. If the performance evaluation solely depends on the teachers' impressions, the formative evaluation will lose its impartiality and credibility, thus affecting the students' participation enthusiasm (Li, Zheng, Feng, Liu, \& Ma, 2019). The assessment carrying out attendance confirmation, in-class test, classroom discussion and online assignments on WeChat Teaching Platform can record and track the students' progress in an all-round way. The new teaching mode adopts formative evaluation which disperses the learning assessment during the whole semester. With a multi-perspective process and effect evaluation of learning, the evaluation system becomes increasingly perfect. WeChat Teaching Platform can track and evaluate each student's learning progress and effect, and generate a learning evaluation report at the end of the semester. Such quantitative evaluation, characterized by its comprehensiveness and objectivity, enhances the credibility and impartiality of the evaluation. Teachers can timely feedback on students' learning progress while optimizing the teaching design in time as per the evaluation caters different students. According to the results of questionnaire, $92.59 \%$ of the students thought that the evaluation in the new teaching mode was fair and credible; 90.74\% thought that the evaluation had got timely feedback; $92.59 \%$ thought that the new learning mode could build a relatively fair evaluation system.

3) The mode facilitated the in-depth integration between information technology and course teaching, and developed students' self-learning ability

The teaching mode based on WeChat flip class and formative evaluation facilitated the in-depth integration between information technology and course teaching, and constructed a mobile learning mode featured with learning "eve- 
rywhere and anywhen". The integration of online and offline modes provided diversified teaching activities, stimulated students' aspiration and developed students' good learning habits (Jiang et al., 2019). At the stage of pre-class knowledge instruction, we conducted the resource transfer on WeChat to improve the effect of students' independent learning. The students came to the classroom with questions in their mind, which could improve the effect of classroom discussion. At the stage of knowledge assimilation, we carried out online and offline teaching activities flexibly and easily on WeChat Teaching Platform. During the problem discussion, the students played the dominant role, with the teachers playing a leading role and giving timely instructions. More points would be awarded to the students who participated in the discussion more actively. At the stage of post-class consolidation and development, the students could consolidate and expand their knowledge with the learning resources provided by WeChat. Students with extra time and energy could utilize their knowledge in their teachers' scientific research programs. By such means, the knowledge transfer and socialization provided by WeChat helped operate flip class more flexibly and conveniently, thereby significantly improving the students' initiatives in independent learning. According to the result of questionnaire, $94.44 \%$ of the students were satisfied with the pre-class self-learning instruction and pre-class resource transfer; $90.74 \%$ of them thought that the new teaching mode had improved the learning ability at fragmented time and helped expand their knowledge; $98.15 \%$ thought that the new learning mode was conducive to the extension of classroom teaching; $96.30 \%$ thought that the new learning mode had helped expand the classroom teaching; $96.30 \%$ thought that the new learning method was conducive to independent learning.

\section{Conclusion}

In the era of "Internet plus Education", teachers shall make good use of mobile teaching platform to instruct students and improve their participation in classroom teaching. The joint teaching mode based on WeChat flip class and formative evaluation embodies the "student-centered" teaching concept, highlights the in-depth integration between information technology and curriculum, and constructs a mobile learning mode featured with learning "everywhere and anywhen". WeChat has greatly facilitated the effective implementation of formative evaluation. The collection of all the information concerning students' learning via WeChat, and such activities as attendance sign-in, in-class test, classroom questioning and classroom discussion has promoted the generation of a comprehensive, objective and fair formative evaluation system, which helped stimulate students' interest in learning and developing their self-learning ability. Of course, none of teaching modes can be deemed omnipotent. In the implementation process, such problems as difficulty in catering to every single student in a large-scale collective class, teachers' comprehensive quality to be further improved and students' proper application of their phones still exist. Therefore, 
while implementing the new teaching mode, teachers must enhance their information-based teaching ability and teaching management ability as well, which will lead to a win-win result, making it worthy of continuous optimization and promotion in teaching. We will keep improving the teaching platform, intriguing students with pleasant learning experience, and serving students with high-quality learning resources.

\section{Fund Program}

The 2017 Guangxi Vocational Education Teaching Reform Research Project + "Research and Practice of Flip Classroom Based on WeChat Platform Combined with Formative Evaluation in Teaching-Taking Higher Vocational Analysis and Testing Related Courses as an Example" + (GXGZJG2017A057).

\section{Conflicts of Interest}

The authors declare no conflicts of interest regarding the publication of this paper.

\section{References}

Chen, X. (2017). Research on College English Classroom Teaching Evaluation Based on Mobile Terminals-Illustrated by "Moso Tech". Light Industry Science and Technology, 33, 157-158.

Jiang, Q., Li, Y., Sun, J., Zhao, W., \& Liu, H. (2019). Self-Adaptive Hybrid MOOC Mode-A New Paradigm of MOOC Design. China Educational Technology, No. 9, 82-90.

Li, J., Zheng, Y., Feng, W., Liu, H., \& Ma, D. (2019). Formative Evaluation on the Course of Strengthened Instrumental Analysis Based on Moso Tech Class. Health Vocational Education, 37, 41-42.

Ma, K., Cai, B., Li, L., Na, S., Song, R., \& Xu, Z. (2018). Application of Flip Class as a New Teaching Mode in Biochemistry Teaching. Journal of Youjiang Medical University for Nationalities, 40, 615-617.

Wang, G., Zhang, Q., Shi, S., Wang, X., \& Li, M. (2019). Teaching Practice and Reform of Instrumental Analysis Course. University Education, No. 2, 74-76.

Wang, P., Gong, L., Zhu, X., Yang, J., Gao, J., He, J., Lin, A., \& Bu, W. (2020). Practical Exploration of Formative Evaluation Based on Rain Classroom Teaching Mode in Genetics Teaching. Journal of Youjiang Medical University for Nationalities, 42, 385-388+391.

Weng, T. (2018). Research on the Construction of Formative Evaluation System for English Translation Teaching in Higher Vocational Colleges in the Context of Big Data-Illustrated by "Moso Tech". English Teachers, 18, 18-20+23. 